\title{
Analisis Beban Kerja Pekerja Pada Gedung 1 Departemen Produksi PT. Sunthi Sepuri Menggunakan Metode Full Time Equivalen (FTE)
}

\author{
Sukirman $^{1}$, Ismi Mashabai*2 ${ }^{*}$ dan Ikhsan Adiasa $^{3}$ \\ 1,2,3 Teknik Industri, Fakultas Teknik, Universitas Teknologi Sumbawa, \\ J1. Raya Olat Maras, Kabupaten Sumbawa, Nusa Tenggara Barat. 84371, Indonesia \\ Email: sukimotto96@gmail.com ${ }^{1}$, ismi.mashabai@uts.ac.id ${ }^{2}$,iksan.adiasa@uts.ac.id ${ }^{3}$
}

\begin{abstract}
Abstrak
Perkembangan industri saat ini semakin pesat baik dalam bidang manufaktur maupun jasa. Berkembangnya perindustrian ini sangat memberikan dampak yang positif bagi negara maupun perusahaan sendiri. Baik secara langsung maupun tidak langsung. PT Sunthi Sepuri (PT. SS) merupakan perusahan nasional yang memproduksi dan memasarakan produk farmasi. PT Sunthi Sepuri (PT. SS) berkomitmen tinggi terhadap standar kualitas yang baik sehingga dapat menghasilkan produk yang dipercaya dan memuaskan pelanggan. Kualitas produk farmasi harus dijaga kualitasnya karena menyangkut kesehatan masyarakat, oleh karena itu operator yang bekerja diperusahaan tersebut harus bekerja secara profesional. Agar operator bekerja dengan profesional beban kerja harus dibagikan sesuai dengan beban yang distandarkan pemerintah. Metode yang digunakan oleh peneliti dalam menganalisi beban kerja adalah metode FTE (full time equivalen). Metode ini digunakan oleh peneliti karena sesuai dengan kondisi yang ada diperusahaan. Area yang diteliti adalah departemen produksi PT. Sunthi Sepuri (PT. SS). Hal ini dilakukan karena keterbatasan departemen yang diberikan izin masuk oleh perusahaan. Selain itu, proses produksi diambil peneliti karena sesuai dengan konsentrasi keahlian penelitian yakni manufaktur. Hasil didapatkan dari penelitian yang telah dilakukan adalah bahwa dari lima operator, operator mesin blistering dan operator mesin compressing 4 memiliki beban kerja yang overload (berlebih), sehingga perlu dilakukan penambahan masing-masing satu orang operator di kedua stasiun kerja tersebut.
\end{abstract}

Kata kunci: proses produksi, perencanaan SDM, analisis beban kerja, full time eqivalent

\begin{abstract}
Industrial development is currently growing rapidly both in manufacturing and services. The development of this industry has had a very positive impact on both the country and the company itself. Either directly or indirectly. PT Sunthi Sepuri (PT. SS) is a national company that produces and markets pharmaceutical products. PT Sunthi Sepuri (PT. SS) is highly committed to good quality standards so as to produce products that are trusted and satisfy customers. The quality of pharmaceutical products must be maintained because of their concern for public health, therefore operators working in these companies must work professionally. In order for operators to work with professionals the workload must be shared according to government standard loads. The method used by researchers in analyzing workloads is the FTE (full time equivalent) method. This method is used by researchers because it is in accordance with existing conditions in the company. The area studied is the production department of PT. Sunthi Sepuri (PT. SS). This is done because of the limitations of the department that is granted entry permits by the company. In addition, the production process is taken by researchers because it is in accordance with the concentration of research expertise, namely manufacturing. The results obtained from the research that have been done are that of the five operators, the blistering machine operator and the compressor 4 operator have an overloaded workload, so it is necessary to add one operator each in the two work stations.
\end{abstract}

Keywords: production process, HR planning, workload analysis, full time equivalent

\section{Pendahuluan}

PT Sunthi Sepuri (PT. SS) merupakan perusahaan nasional yang memproduksi dan memasarakan produk farmasi. PT Sunthi Sepuri (PT. SS) berkomitmen tinggi terhadap standar kualitas yang baik sehingga dapat menghasilkan produk yang dapat dipercaya dan memuaskan pelanggan. Kualitas produk farmasi harus dijaga kualitasnya karena menyangkut kesehatan masyarakat, oleh karena itu operator yang bekerja diperusahaan tersebut harus bekerja secara profesional. Agar operator bekerja dengan profesional beban kerja harus dibagikan sesuai dengan beban yang distandarkan pemerintah.

\footnotetext{
${ }^{*}$ Penulis korespondensi
} 
Analisis beban kerja merupakan metode yang digunakan untuk menentukan jumlah atau kuantitas tenaga kerja yang diperlukan (Aristi dan Hafiar, 2018). Beban kerja yang didistribusikan secara tidak merata dapat mengakibatkan ketidaknyamanan suasana kerja, karena operator merasa beban kerja yang dilakukannya terlalu berlebihan atau kekurangan (Tridoyo dan Sriyanto, 2014).

Penelitian ini membahas mengenai analisis beban kerja menggunakan metode FTE (full time equivalen). Metode ini digunakan oleh peneliti karena sesuai dengan kondisi yang ada diperusahaan. Area yang diteliti adalah departemen produksi PT. Sunthi Sepuri (PT. SS). Hal ini dilakukan karena keterbatasan departemen yang diberikan izin masuk oleh perusahaan. Selain itu, proses produksi diambil peneliti karena sesuai dengan konsentrasi keahlian penelitian yakni manufaktur. Diharapkan dengan dilakukan penelitian ini agar dapat menjadi acuan dan pertimbangan dalam kebijakan menentukan jumlah operator proses rekruitmen mendatang.

\section{Metode Penelitian}

Penelitian ini dilakukan di PT. Sunthi Sepuri khususnya di departemen produksi. Adapun objek penelitian ini yaitu operator yang berada di departemen produksi. Analisis beban kerja pada penelitian ini dilakukan dengan menggunakan metode Full Time Equivalent (FTE). Menurut Dewi dan Satrya (2012), Full Time Equivalent adalah salah satu metode analisis beban kerja yang berbasiskan waktu dengan cara mengukur lama waktu penyelesaian pekerjaan kemudian waktu tersebut dikonversikan ke dalam indeks nilai FTE. Metode perhitungan beban kerja dengan full time equivalent (FTE) adalah metode dimana waktu yang digunakan untuk menyelesaikan berbagai pekerjaan dibandingkan terhadap waktu kerja efektif yang tersedia (Yasmin \& Ariyanti, 2019). FTE bertujuan menyederhanakan pengukuran kerja dengan mengubah jam beban kerja ke jumlah orang yang dibutuhkan untuk menyelesaikan pekerjaan tertentu (Adawiyah, 2013). Untuk mendapatkan nilai FTE dari suatu proses kerja rumusnya adalah sebagai berikut. FTE $=$

Total waktu aktivitas + Total waktu allowance Total waktu kerja dalam setahun $\times 100 \%$

Menurut Dewi dan Satriya (2012) dalam melakukan analisis beban kerja dengan metode FTE (Full Time Equivalent) terdapat lima langkah yang perlu dilakukan yaitu pertama menetapkan unit kerja beserta kategori tenaganya, kedua menetapkan waktu kerja yang tersedia selama satu tahun. Data yang dibutuhkan untuk menetapkan waktu kerja dalam setahun adalah: hari kerja, cuti tahunan, pendidikan dan pelatihan, hari libur nasional, ketidakhadiran kerja, dan waktu kerja (Hudaningsih, 2019). Ketiga menyusun standar kelonggaran tujuan dari menyusun data ini adalah untuk mengetahui faktor kelonggaran (allowance) operator yang meliputi jenis kegiatan dan kebutuhan waktu dalam menyelesaikan suatu kegiatan yang tidak terkait dengan kegiatan pokoknya. Kegiatan yang tidak terkait langsung contohnya adalah istirahat, sholat atau ke toilet dan beberapa kegiatan lainnya. Keempat menetapkan standar beban kerja yang merupakan volume beban kerja yang dirasakan oleh operator dalam menyelesaikan pekerjaannya (rata-rata waktu). Kelima menghitung kebutuhan tenaga per unit kerja. Pada tahap ini peneliti berusaha memperoleh jumlah dan kategori operator yang kerja sesuai dengan beban kerja. Dalam perhitungan FTE, untuk mendapatkan total waktu aktivitas, total waktu allowance dan total waktu kerja adalah sebagai berikut:

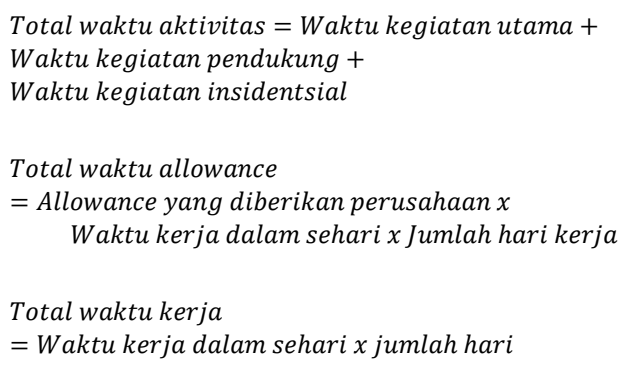

Berdasarkan pedoman analisis beban kerja dari badan kepegawaian Indonesia Tahun 2010, beban kerja dapat dibedakan menjadi tiga bagian yang dapat dilihat pada tabel 1 berikut ini:

Tabel 1. Kategori Beban Kerja Notasi

\begin{tabular}{lc}
\hline Kategori Beban Kerja & FTE \\
\hline Overload & $>1,28$ \\
Normal/fit & $1>\mathrm{x}<1,27$ \\
Underload & $<0,99$ \\
\hline
\end{tabular}

\section{Hasil dan Pembahasan}

Perhitungan beban kerja dengan menggunakan metode full time equivalent (FTE) adalah waktu yang digunakan untuk menyelesaikan berbagai pekerjaan dibandingkan terhadap waktu kerja efektif yang tersedia. FTE bertujuan menyederhanakan pengukuran kerja dengan mengubah jam beban kerja ke jumlah orang yang dibutuhkan untuk menyelesaikan pekerjaan tertentu (Adawiyah, 2013). Berikut adalah tahapan untuk mendapatkan nilai FTE dari sutau proses kerja :

\subsection{Allowance}

Waktu allowance adalah waktu yang digunakan untuk kegiatan pribadi seperti beristirahat, sholat, makan ke toilet dan sebagainya. Pada perusahaan PT. Sunthi Sepuri, bagian produksi dalam mengambil data mengenai beban kerja ini diberikan kelonggaran yaitu sebesar $25 \%$ dari jam kerja. Allowance tersebut ditentukan oleh perusahaan yang diberikan kepada tenaga kerja bagian 
produksi. Berikut adalah data jumlah operator bagian produksi yang diamati yang ditunjukkan pada tabel 2 .

\begin{tabular}{ccc}
\multicolumn{2}{c}{ Tabel } & 2. Jumlah Operator Bagian Produksi yang Diamati \\
\hline No & \multicolumn{1}{c}{ Nama Jabatan } & Jumlah Operator \\
\hline 1 & Operator Mesin Mixing 1 & 2 orang \\
2 & Operator Mesin Compressing 2 & 1 orang \\
3 & Operator Mesin Blistering & 2 orang \\
4 & Operator Mesin Stripping & 2 orang \\
5 & Operator Mesin Compressing 4 & 1 orang \\
\hline
\end{tabular}

Selanjutnya dilakukan perhitungan beban kerja dari masing-masing bagian produksi yang diamati menggunakan metode FTE.

\section{A. Beban Kerja Operator Mesin Mixing 1}

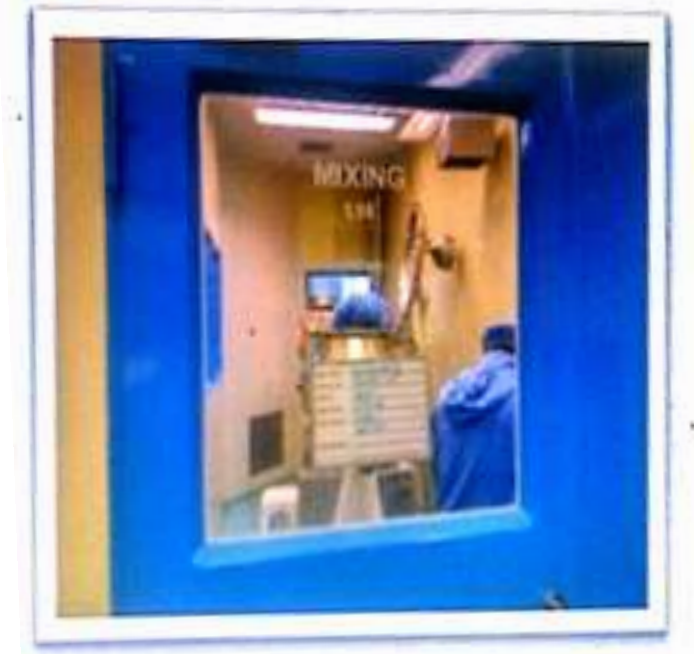

Gambar 1. Kegiatan di Mesin Mixing 1 di Perusahaan PT. Sunthi Sepuri

Perhitungan Waktu Kerja Operator Mesin Mixing 1 dapat dilihat pada Lampiran 1. Dengan menggunakan rumus persamaan (2) maka di peroleh total waktu aktivitas sebagai adalah berikut :

Total Waktu Aktivitas

= Waktu Kegiatan Utama + Waktu Kegiatan Pendukung

+ Waktu Kegiatan Insidental

$=244800+0+1440$

$=246240$ menit

Dengan menggunakan rumus persamaan (3) maka di peroleh total waktu allowance sebagai berikut :

Total Waktu Allowance

$=$ Allowance yang diberikan perusahaan $\times$ waktu kerja dalam sehari $\times$ Jumlah hari kerja

$=(25 \%) \times(60$ menit $\times 8$ jam $) \times(240$ hari $)$

$=28800$ menit
Dengan menggunakan rumus persamaan (4) maka di peroleh total waktu kerja adalah sebagai berikut :

Total Waktu Kerja

$=$ Waktu Kerja dalam sehari $\times$ Jumlah hari

$=(60$ menit $\times 8$ jam $) \times(240$ hari $)$

$=115.200$ menit

Setelah di peroleh total waktu aktivitas, total waktu allowance, dan total waktu kerja, maka dengan menggunakan persamaan rumus (1) di peroleh full time equivalent adalah sebagai berikut :

$$
\begin{aligned}
\text { FTE } & =\frac{\text { Total waktu aktivitas }+ \text { total waktu allowance }}{\text { total waktu kerja dalam setahun }} \\
& =\frac{246240+28.800}{115.200} \times 100 \% \\
& =239 \%=2,39
\end{aligned}
$$

Setelah dilakukan perhitungan dengan menggunakan metode FTE, didapatkan beban kerja operator mesin mixing adalah $239 \%$ atau 2,39. Hasil tersebut menunjukkan beban berlebih. Namun dikarenakan jumlah aktual yang menjabat sebagai operator mesin Mixing adalah 2 orang atau dengan pembagian menjadi masing-masing operator memiliki beban 1,195, maka sesuai dengan kategori beban kerja FTE, untuk operator mesin mixing tidak diperlukan penambahan jumlah operator dalam kebijakan rekrutmen mendatang.

\section{B. Beban Kerja Operator Mesin Compressing 2}

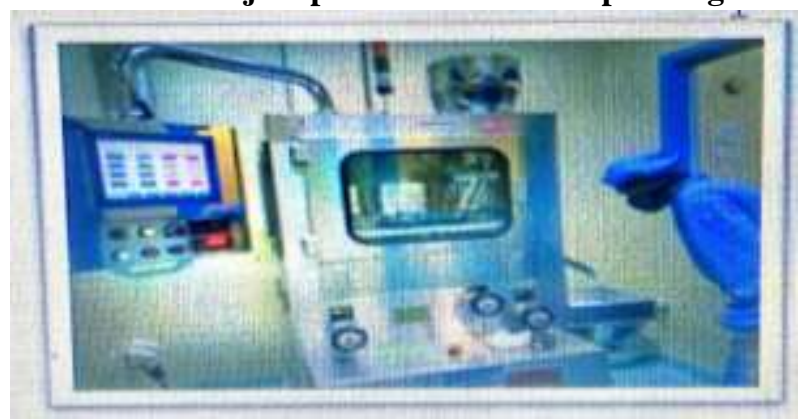

Gambar 2. Kegiatan di Mesin Compressing 2 di Perusahaan PT. Sunthi Sepuri

Perhitungan Waktu Kerja Operator Mesin Mixing 1 dapat dilihat pada Lampiran 2. Dengan menggunakan rumus persamaan (2) maka di peroleh total waktu aktivitas sebagai adalah berikut :

Total Waktu Aktivitas $=114000+0+720$

$$
=114720 \text { menit }
$$

Dengan menggunakan rumus persamaan (3) maka di peroleh total waktu allowance sebagai berikut :

Total Waktu Allowance

$$
\begin{aligned}
& =(25 \%) \times(60 \text { menit } \times 8 \text { jam }) \times(240 \text { hari }) \\
& =28800 \text { menit }
\end{aligned}
$$

Dengan menggunakan rumus persamaan (4) maka di peroleh total waktu kerja adalah sebagai berikut : 
Total Waktu Kerja

$=(60$ menit $\times 8$ jam $) \times(240$ hari $)$

$=115.200$ menit

Setelah di peroleh total waktu aktivitas, total waktu allowance, dan total waktu kerja, maka dengan menggunakan persamaan rumus (1) diperoleh full time equivalent adalah sebagai berikut :

$$
\begin{aligned}
\text { FTE } & =\frac{114720+28.800}{115.200} \times 100 \% \\
& =124,6 \%=1,246
\end{aligned}
$$

Setelah dilakukan perhitungan dengan menggunakan metode FTE, didapatkan beban kerja operator mesin compressing adalah $124,6 \%$ atau 1,246 . Hasil tersebut menunjukkan beban kerja normal. Sesuai dengan kategori beban kerja FTE, untuk operator mesin compressing 2 tidak diperlukan penambahan jumlah operator dalam kebijakan rekrutmen mendatang.

\section{Beban Kerja Operator Mesin Blistering}

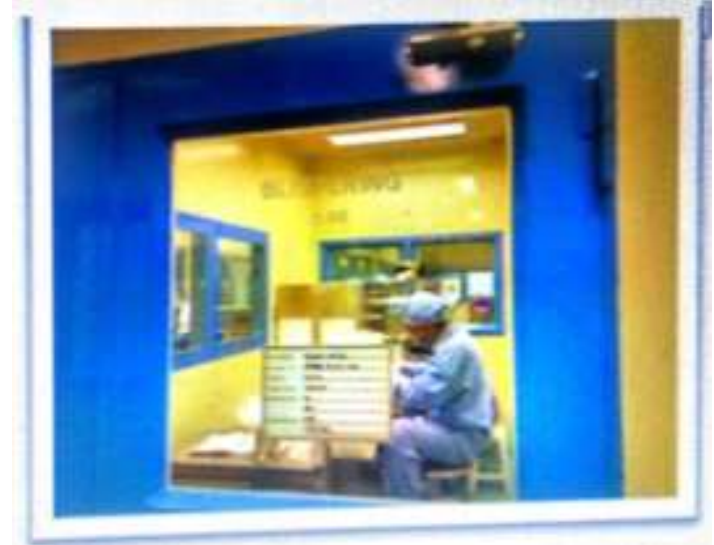

Gambar 3. Kegiatan di Mesin Blistering di Perusahaan PT. Sunthi Sepuri

Perhitungan Waktu Kerja Operator Mesin Mixing 1 dapat dilihat pada Lampiran 3. Dengan menggunakan rumus persamaan (2) maka di peroleh total waktu aktivitas sebagai adalah berikut :

Total Waktu Aktivitas

$$
\begin{aligned}
& =312000+0+1440 \\
& =313440 \text { menit }
\end{aligned}
$$

Dengan menggunakan rumus persamaan (3) maka di peroleh total waktu allowance sebagai berikut :

Total Waktu Allowance

$$
\begin{aligned}
& =(25 \%) \times(60 \text { menit } \times 8 \text { jam }) \times(240 \text { hari }) \\
& =28800 \text { menit }
\end{aligned}
$$

Dengan menggunakan rumus persamaan (4) maka di peroleh total waktu kerja adalah sebagai berikut :

Total Waktu Kerja

$$
\begin{aligned}
& =(60 \text { menit } \times 8 \text { jam }) \times(240 \text { hari }) \\
& =115.200 \text { menit }
\end{aligned}
$$

Setelah di peroleh total waktu aktivitas, total waktu allowance, dan total waktu kerja, maka dengan menggunakan persamaan rumus (1) di peroleh full time equivalent adalah sebagai berikut :

$$
\begin{aligned}
\text { FTE } & =\frac{313440+28.800}{115.200} \times 100 \% \\
& =297 \%=2,97
\end{aligned}
$$

Setelah dilakukan perhitungan dengan menggunakan metode FTE, didapatkan beban kerja operator mesin mixing adalah $297 \%$ atau 2,97. Hasil tersebut menunjukkan beban berlebih. Namun dikarenakan jumlah aktual yang menjabat sebagai operator mesin blistering adalah 2 orang atau dengan pembagian menjadi masing-masing operator memiliki beban 1,485, maka sesuai dengan kategori beban kerja FTE, untuk operator mesin blistering memerlukan penambahan satu orang operator dalam kebijakan rekrutmen mendatang karena beban kerja yang berlebih.

\section{Beban Kerja Operator Mesin Stripping}

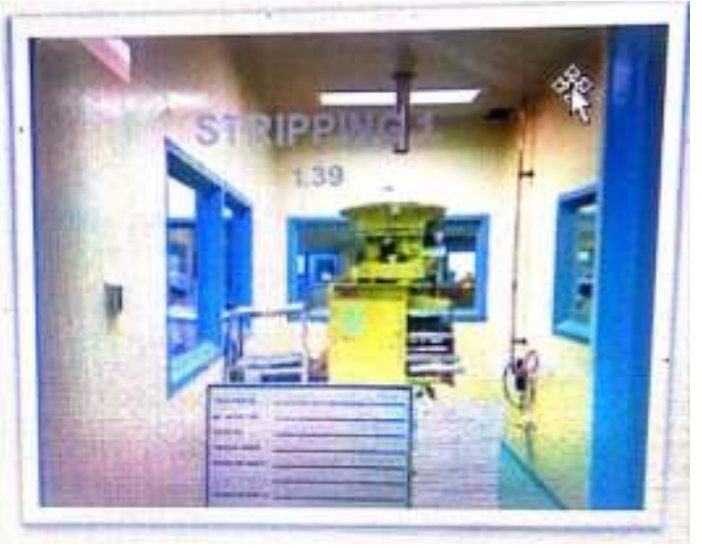

Gambar 4. Kegiatan di Mesin Stripping di Perusahaan PT. Sunthi Sepuri

Perhitungan Waktu Kerja Operator Mesin Mixing 1 dapat dilihat pada Lampiran 4. Dengan menggunakan rumus persamaan (2) maka di peroleh total waktu aktivitas sebagai adalah berikut :

Total Waktu Aktivitas

$$
\begin{aligned}
& =240000+0+1440 \\
& =241440 \text { menit }
\end{aligned}
$$

Dengan menggunakan rumus persamaan (3) maka di peroleh total waktu allowance sebagai berikut :

Total Waktu Allowance

$$
\begin{aligned}
& =(25 \%) \times(60 \text { menit } \times 8 \text { jam }) \times(240 \text { hari }) \\
& =28800 \text { menit }
\end{aligned}
$$

Dengan menggunakan rumus persamaan (4) maka di peroleh total waktu kerja adalah sebagai berikut : Total Waktu Kerja

$$
\begin{aligned}
& =(60 \text { menit } \times 8 \text { jam }) \times(240 \text { hari }) \\
& =115.200 \text { menit }
\end{aligned}
$$


Setelah diperoleh total waktu aktivitas, total waktu allowance, dan total waktu kerja, maka dengan menggunakan persamaan rumus (1) di peroleh full time equivalent adalah sebagai berikut :

$$
\begin{aligned}
\text { FTE } & =\frac{241440+28.800}{115.200} \times 100 \% \\
& =235 \%=2,35
\end{aligned}
$$

Setelah dilakukan perhitungan dengan menggunakan metode FTE, didapatkan beban kerja operator mesin stripping adalah $235 \%$ atau 2,35. Hasil tersebut menunjukkan beban kerja berlebih. Namun dikarenakan jumlah aktual yang menjabat sebagai operator mesin stripping adalah 2 orang atau dengan pembagian menjadi masing-masing operator memiliki beban 1,175, maka sesuai dengan kategori beban kerja FTE, untuk operator mesin stripping tidak perlu adanya penambahan jumlah operator dalam kebijakan rekrutmen mendatang.

\section{E. Beban Kerja Operator Mesin Compressing 4}

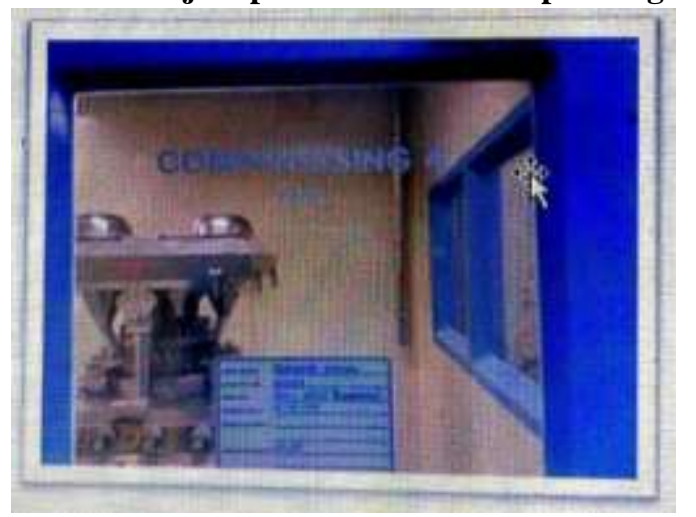

Gambar 5. Kegiatan di Mesin Compressing 4 di Perusahaan PT. Sunthi Sepuri

Perhitungan Waktu Kerja Operator Mesin Mixing 1 dapat dilihat pada Lampiran 5. Dengan menggunakan rumus persamaan (2) maka di peroleh total waktu aktivitas sebagai adalah berikut :

Total Waktu Aktivitas

$$
\begin{aligned}
& =192000+0+720 \\
& =192720 \text { menit }
\end{aligned}
$$

Dengan menggunakan rumus persamaan (3) maka di peroleh total waktu allowance sebagai berikut :

Total Waktu Allowance

$$
\begin{aligned}
& =(25 \%) \times(60 \text { menit } \times 8 \text { jam }) \times(240 \text { hari }) \\
& =28800 \text { menit }
\end{aligned}
$$

Dengan menggunakan rumus persamaan (4) maka di peroleh total waktu kerja adalah sebagai berikut :

Total Waktu Kerja

$$
\begin{aligned}
& =(60 \text { menit } \times 8 \text { jam }) \times(240 \text { hari }) \\
& =115.200 \text { menit }
\end{aligned}
$$

Setelah di peroleh total waktu aktivitas, total waktu allowance, dan total waktu kerja, maka dengan menggunakan persamaan rumus (1) di peroleh full time equivalent adalah sebagai berikut :

$$
\begin{aligned}
\text { FTE } & =\frac{192720+28.800}{115.200} \times 100 \% \\
& =192 \%=1,92
\end{aligned}
$$

Setelah dilakukan perhitungan dengan menggunakan metode FTE, didapatkan beban kerja operator mesin stripping adalah $1,92 \%$ atau 1,92 , Hasil tersebut menunjukkan beban kerja berlebih, maka sesuai dengan kategori beban kerja FTE, untuk operator mesin stripping perlu adanya penambahan satu orang operator dalam kebijakan rekrutmen mendatang.

\subsection{Perbandingan jumlah operator setelah perhitungan FTE}

Dari tabel 3 dapat diketahui nilai beban kerja serta perhitungan jumlah operator yang dibutuhkan tiap departemen kerja yang dihitung menggunakan metode FTE. Dari ke lima departemen kerja, didapatkan bahwa operator mesin blistering dan operator mesin compressing 4 memiliki beban kerja yang overload (berlebih) dan perlu adanya penambahan jumlah operator pada departemen tersebut agar porsi kerja sesuai dengan standar. Dengan begitu, dapat dipastikan operator bekerja dengan aman dana nyaman. Selain itu, jika operator bekerja dengan waktu sesuai porsi, akan membuat pekerjaan dapat diselesaikan dengan baik dan menjaga kualitas.

Tabel 3. Perbandingan Jumlah Operator

\begin{tabular}{cccccc}
\hline No & Nama Jabatan & $\begin{array}{c}\text { Beban } \\
\text { Kerja } \\
\text { (FTE) }\end{array}$ & $\begin{array}{c}\text { Jumlah } \\
\text { Operator } \\
\text { Awal }\end{array}$ & $\begin{array}{c}\text { Jumlah } \\
\text { Operator } \\
\text { (FTE) }\end{array}$ & $\begin{array}{c}\text { Seli- } \\
\text { sih }\end{array}$ \\
\hline 1 & $\begin{array}{l}\text { Operator Mesin } \\
\text { Mixing 1 } \\
2\end{array}$ & 2,39 & 2 & 2 & 0 \\
3 & $\begin{array}{l}\text { Operator Mesin } \\
\text { Compressing 2 } \\
\text { Operator Mesin } \\
\text { Blistering } \\
\text { Operator Mesin }\end{array}$ & 1,246 & 1 & 1 & 0 \\
5 & $\begin{array}{l}\text { Stripping } \\
\text { Operator Mesin }\end{array}$ & 1,92 & 2 & 3 & 1 \\
\hline Compressing 4 & Total & 1 & 2 & 0 \\
\hline
\end{tabular}

Dari tabel 3 dapat diketahui nilai beban kerja serta perhitungan jumlah operator yang dibutuhkan tiap departemen kerja yang dihitung menggunakan metode FTE. Dari ke lima departemen kerja, didapatkan bahwa operator mesin blistering dan operator mesin compressing 4 memiliki beban kerja yang overload (berlebih) dan perlu adanya penambahan jumlah operator pada departemen tersebut agar porsi kerja sesuai dengan standar. Dengan begitu, dapat dipastikan operator bekerja dengan aman dana nyaman. Selain itu, jika operator bekerja dengan waktu sesuai porsi, akan membuat pekerjaan dapat diselesaikan dengan baik dan menjaga kualitas.

\section{Kesimpulan}


Berdasarkan pengolahan data beban kerja menggunakan metode FTE pada setiap operator yang diamati di departemen produksi PT. Sunthi Sepuri, didapatkan bahwa beban kerja operator mesin yang diamati di departemen produksi PT. Sunthi Sepuri pada mesin mixing 1 adalah sebesar 2,39, pada mesin compressing 2 adalah sebesar 1,23, pada mesin blisstering adalah sebesar $278 \%$, atau 2,78 beban kerja operator mesin stripping adalah sebesar $235 \%$, atau 2,35 dan beban kerja operator mesin compressing 4 adalahh sebesar $235 \%$ atau 2,35

Berdasarkan hasil perhitungan beban kerja, maka dapat diketahui usulan kebutuhan jumlah tenaga kerja dalam hal kebijakan rekruitmen mendatang. Adapun usulan jumlah operator mesin mixing 1 adalah tetap 2 orang, usulan jumlah operator mesin compressing 2 adalah tetap 1 orang, usulan jumlah operator mesin blistering adalah berubah menjadi 3 orang atau penambahan 1 orang operator, usulan operator mesin stripping adalah tetap 2 orang, usulan operator mesin compressing 4 adalah berubah menjadi 2 orang atau penambahan 1 orang operator. Diharapkan dengan adanya penambahan operator tersebut, maka beban kerja pada masing-masing departemen menjadi lebih baik.

\section{Daftar Pustaka}

Adawiyah, W., \& Sukmawati, A. (2013). Analisis beban kerja sumber daya manusia dalam aktivitas produksi komoditi sayuran selada (Studi Kasus:
CV Spirit Wira Utama). Jurnal Manajemen dan Organisasi, 4(2), 128-143.

Aristi, N., \& Hafiar, H. (2014). Analisis beban kerja tenaga pendidik dan kependidikan di Fakultas Y Universitas X. Jurnal Kajian Komunikasi, 2(1), 53-60.

Dewi, U., \& Satrya, A. (2012). Analisis Kebutuhan Tenaga Kerja Berdasarkan Beban Kerja Operator Pada PT PLN (Persero) Distribusi Jakarta Raya dan Tangerang Bidang Sumber Daya Manusia dan Organisasi. Jakarta: Universitas Indonesia.

Hasibuan, M. S., \& Hasibuan, H. M. S. (2016). Manajemen sumber daya manusia. Bumi Aksara.

Hudaningsih, N. (2019). Analisis Kebutuhan Karyawan Dengan Menggunakan Metode Full Time Equivalent (Fte) Pada Departemen Produksi Pt. Borsya Cipta Communica. Jurnal TAMBORA, 3(2), 98-106.

Tridoyo, T., \& Sriyanto, S. (2014). Analisis Beban Kerja Dengan Metode Full Time Equivalent Untuk Mengoptimalkan Kinerja Operator Pada Pt Astra International Tbk-Honda Sales Operation Region Semarang. Industrial Engineering Online Journal, 3(2).

Yasmin, Z. A., \& Ariyanti, S. (2019). Analisis Beban Kerja Pada Maintenance BD-Check Dengan Metode Full Time Equivalent. Jurnal Ilmiah Teknik Industri, 6(1).

Lampiran 1. Perhitungan Waktu Kerja Operator Mesin Mixing 1

\begin{tabular}{|c|c|c|c|c|c|c|c|c|c|c|c|c|}
\hline \multirow[b]{2}{*}{ No } & \multirow[b]{2}{*}{ Kegiatan } & \multirow[b]{2}{*}{ Periode } & \multicolumn{3}{|c|}{$\begin{array}{c}\text { Kaitan Dengan } \\
\text { Tugas }\end{array}$} & \multirow[b]{2}{*}{ 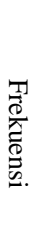 } & \multirow[b]{2}{*}{ 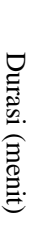 } & \multirow[b]{2}{*}{ 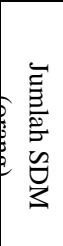 } & \multirow[b]{2}{*}{ 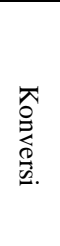 } & \multicolumn{3}{|c|}{ Kaitan Dengan Tugas } \\
\hline & & & 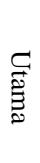 & $\underset{0}{\stackrel{D}{0}}$ & 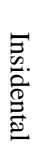 & & & & & 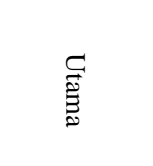 & 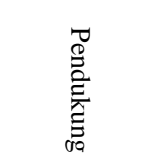 & 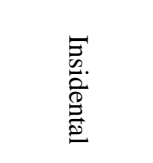 \\
\hline & & & $\mathrm{a}$ & $\mathrm{b}$ & $\mathrm{c}$ & A & $\mathrm{B}$ & $\mathrm{C}$ & $\mathrm{D}$ & axAxbxCxD & bxAxBxCxD & $\operatorname{cxAxBxCxD}$ \\
\hline 1 & Persiapan Mesin & Harian & 1 & 0 & 0 & 1 & 30 & 2 & 240 & 14400 & 0 & 0 \\
\hline 2 & $\begin{array}{c}\text { Pengadukan } \\
\text { Bahan }\end{array}$ & Harian & 1 & 0 & 0 & 4 & 20 & 2 & 240 & 38400 & 0 & 0 \\
\hline 3 & $\begin{array}{c}\text { Penyaringan } \\
\text { Bahan }\end{array}$ & Harian & 1 & 0 & 0 & 4 & 15 & 2 & 240 & 28800 & 0 & \\
\hline 4 & Produksi & Harian & 1 & 0 & 0 & 4 & 10 & 2 & 240 & 19200 & 0 & 0 \\
\hline 5 & $\begin{array}{c}\text { Memasukan } \\
\text { Bahan }\end{array}$ & Harian & 1 & 0 & 0 & 4 & 5 & 2 & 240 & 9600 & 0 & 0 \\
\hline 6 & Sanitasi & Harian & 1 & 0 & 0 & 1 & 60 & 2 & 240 & 28800 & 0 & 0 \\
\hline 7 & $\begin{array}{c}\text { Pembersihan } \\
\text { Mesin }\end{array}$ & Harian & 1 & 0 & 0 & 4 & 10 & 2 & 240 & 19200 & 0 & 0 \\
\hline 8 & Breakdown & Harian & 1 & 0 & 0 & 3 & 60 & 2 & 240 & 86400 & 0 & 0 \\
\hline 9 & Pelatihan & Tahunan & 0 & 0 & 1 & 1 & 60 & 2 & 12 & 0 & 0 & 1440 \\
\hline \multicolumn{10}{|c|}{ Beban Kerja } & 244800 & 0 & 1440 \\
\hline
\end{tabular}


Lampiran 2. Perhitungan Waktu Kerja Operator Mesin Compressing 2

\begin{tabular}{|c|c|c|c|c|c|c|c|c|c|c|c|c|}
\hline \multirow[b]{2}{*}{ No } & \multirow[b]{2}{*}{ Kegiatan } & \multirow[b]{2}{*}{ Periode } & \multicolumn{3}{|c|}{$\begin{array}{c}\text { Kaitan Dengan } \\
\text { Tugas }\end{array}$} & \multirow[b]{2}{*}{ 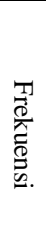 } & \multirow[b]{2}{*}{ 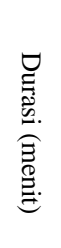 } & \multirow[b]{2}{*}{ 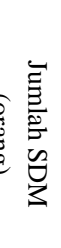 } & \multirow[b]{2}{*}{ 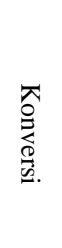 } & \multicolumn{3}{|c|}{ Kaitan Dengan Tugas } \\
\hline & & & 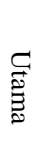 & 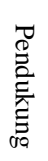 & 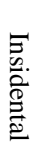 & & & & & 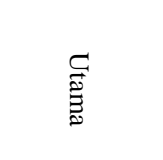 & 总 & 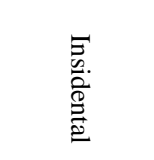 \\
\hline & & & $\mathrm{a}$ & $\mathrm{b}$ & $\mathrm{c}$ & A & B & $\mathrm{C}$ & $\mathrm{D}$ & $\operatorname{axAxbxCxD}$ & bxAxBxCxD & $\operatorname{cxAxBxCxD}$ \\
\hline 1 & Sanitasi/Pembersihan & Harian & 1 & 0 & 0 & 2 & 60 & 1 & 240 & 28800 & 0 & 0 \\
\hline 2 & Setting Mesin & Harian & 1 & 0 & 0 & 1 & 60 & 1 & 240 & 14400 & 0 & 0 \\
\hline 3 & $\begin{array}{c}\text { Pengambilan } \\
\text { Material }\end{array}$ & Harian & 1 & 0 & 0 & 2 & 5 & 1 & 240 & 2400 & 0 & 0 \\
\hline 4 & Produksi & Harian & 1 & 0 & 0 & 1 & 240 & 1 & 240 & 57600 & 0 & 0 \\
\hline 5 & Pengecekan Rutin & Harian & 1 & 0 & 0 & 3 & 15 & 1 & 240 & 10800 & 0 & 0 \\
\hline 6 & Pelatihan & Tahunan & 0 & 0 & 1 & 1 & 60 & 1 & 12 & 0 & 0 & 720 \\
\hline \multicolumn{10}{|c|}{ Beban Kerja } & 114000 & 0 & 720 \\
\hline
\end{tabular}

Lampiran 3. Perhitungan Waktu Kerja Operator Mesin Blistering

\begin{tabular}{|c|c|c|c|c|c|c|c|c|c|c|c|c|}
\hline \multirow[b]{2}{*}{ No } & \multirow[b]{2}{*}{ Kegiatan } & \multirow[b]{2}{*}{ Periode } & \multicolumn{3}{|c|}{$\begin{array}{c}\text { Kaitan Dengan } \\
\text { Tugas }\end{array}$} & \multirow[b]{2}{*}{ 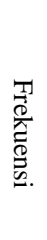 } & \multirow[b]{2}{*}{ 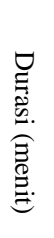 } & \multirow[b]{2}{*}{ 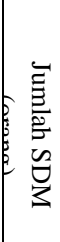 } & \multirow[b]{2}{*}{$\begin{array}{l}\text { त्र } \\
\stackrel{0}{0} \\
0 \\
0 \\
0 .\end{array}$} & \multicolumn{3}{|c|}{ Kaitan Dengan Tugas } \\
\hline & & & 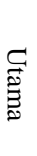 & & 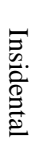 & & & & & 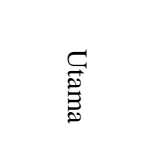 & 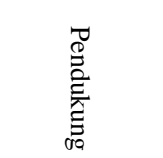 & 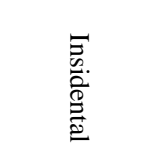 \\
\hline & & & $\mathrm{a}$ & $\mathrm{b}$ & $\mathrm{c}$ & A & B & $\mathrm{C}$ & $\mathrm{D}$ & axAxbxCxD & bxAxBxCxD & $\operatorname{cxAxBxCxD}$ \\
\hline 1 & Persiapan Mesin & Harian & 1 & 0 & 0 & 1 & 60 & 2 & 240 & 28800 & 0 & 0 \\
\hline 2 & Sanitasi & Harian & 1 & 0 & 0 & 1 & 60 & 2 & 240 & 28800 & 0 & 0 \\
\hline 3 & $\begin{array}{c}\text { Pengambilan } \\
\text { Material }\end{array}$ & Harian & 1 & 0 & 0 & 1 & 5 & 2 & 240 & 2400 & 0 & 0 \\
\hline 4 & Produksi & Harian & 1 & 0 & 0 & 1 & 360 & 2 & 240 & 172800 & 0 & 0 \\
\hline 5 & $\begin{array}{c}\text { Pengecekan } \\
\text { Rutin }\end{array}$ & Harian & 1 & 0 & 0 & 3 & 15 & 2 & 240 & 21600 & 0 & 0 \\
\hline 6 & $\begin{array}{c}\text { Pembersihan } \\
\text { Mesin }\end{array}$ & Harian & 1 & 0 & 0 & 1 & 60 & 2 & 240 & 28800 & 0 & 0 \\
\hline 7 & Breakdown & Harian & 1 & 0 & 0 & 1 & 15 & 2 & 240 & 7200 & 0 & 0 \\
\hline 8 & Pelatihan & Tahunan & 0 & 0 & 1 & 1 & 60 & 2 & 12 & 0 & 0 & 1440 \\
\hline \multicolumn{10}{|c|}{ Beban Kerja } & 312000 & 0 & 1440 \\
\hline
\end{tabular}

Lampiran 4. Perhitungan Waktu Kerja Operator Mesin Stripping

\begin{tabular}{|c|c|c|c|c|c|c|c|c|c|c|c|c|}
\hline \multirow[b]{2}{*}{ No } & \multirow[b]{2}{*}{ Kegiatan } & \multirow[b]{2}{*}{ Periode } & \multicolumn{3}{|c|}{$\begin{array}{c}\text { Kaitan Dengan } \\
\text { Tugas }\end{array}$} & \multirow[b]{2}{*}{$\begin{array}{l}\frac{T}{\overrightarrow{0}} \\
\frac{0}{\hat{C}} \\
\stackrel{0}{0} \\
0 .\end{array}$} & \multirow[b]{2}{*}{ 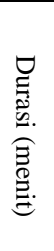 } & \multirow[b]{2}{*}{ 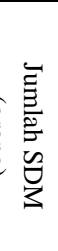 } & \multirow[b]{2}{*}{ 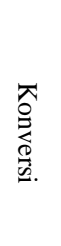 } & \multicolumn{3}{|c|}{ Kaitan Dengan Tugas } \\
\hline & & & 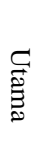 & 总 & 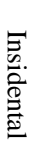 & & & & & 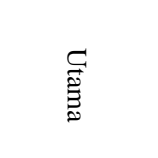 & 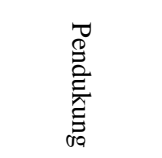 & $\begin{array}{l}\vec{\Xi} \\
\frac{0}{0} \\
\frac{0}{0} \\
\stackrel{0}{\vec{D}}\end{array}$ \\
\hline & & & $\mathrm{a}$ & $\mathrm{b}$ & $\mathrm{c}$ & A & B & $\mathrm{C}$ & $\mathrm{D}$ & axAxbxCxD & bxAxBxCxD & $\operatorname{cxAxBxCxD}$ \\
\hline 1 & $\begin{array}{l}\text { Persiapan } \\
\text { Mesin }\end{array}$ & Harian & 1 & 0 & 0 & 1 & 60 & 2 & 240 & 28800 & 0 & 0 \\
\hline 2 & Sanitasi & Harian & 1 & 0 & 0 & 1 & 60 & 2 & 240 & 28800 & 0 & 0 \\
\hline 3 & $\begin{array}{c}\text { Pengambilan } \\
\text { Material }\end{array}$ & Harian & 1 & 0 & 0 & 1 & 5 & 2 & 240 & 2400 & 0 & 0 \\
\hline 4 & Produksi & Harian & 1 & 0 & 0 & 1 & 300 & 2 & 240 & 144000 & 0 & 0 \\
\hline 5 & $\begin{array}{c}\text { Pengecekan } \\
\text { Rutin }\end{array}$ & Harian & 1 & 0 & 0 & 3 & 5 & 2 & 240 & 7200 & 0 & 0 \\
\hline 6 & $\begin{array}{c}\text { Pembersihan } \\
\text { Mesin }\end{array}$ & Harian & 1 & 0 & 0 & 1 & 60 & 2 & 240 & 28800 & 0 & 0 \\
\hline 7 & Pelatihan & Tahunan & 0 & 0 & 1 & 1 & 60 & 2 & 12 & 0 & 0 & 1440 \\
\hline & & & ban & rja & & & & & & 240000 & 0 & 1440 \\
\hline
\end{tabular}


Lampiran 5. Perhitungan Waktu Kerja Operator Mesin Compressing 4

\begin{tabular}{|c|c|c|c|c|c|c|c|c|c|c|c|c|}
\hline \multirow[b]{2}{*}{ No } & \multirow[b]{2}{*}{ Kegiatan } & \multirow[b]{2}{*}{ Periode } & \multicolumn{3}{|c|}{$\begin{array}{c}\text { Kaitan Dengan } \\
\text { Tugas }\end{array}$} & \multirow[b]{2}{*}{$\begin{array}{l}\text { T. } \\
\stackrel{0}{0} \\
\stackrel{0}{0} \\
\stackrel{\Xi}{0} .\end{array}$} & \multirow[b]{2}{*}{ 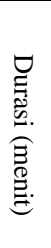 } & \multirow[b]{2}{*}{ 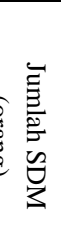 } & \multirow[b]{2}{*}{$\begin{array}{l}\text { त్ } \\
\stackrel{0}{0} \\
\stackrel{0}{0} \\
0.0 \\
0 .\end{array}$} & \multicolumn{3}{|c|}{ Kaitan Dengan Tugas } \\
\hline & & & $\underset{\stackrel{\Xi}{\Xi}}{\stackrel{\Xi}{\Xi}}$ & 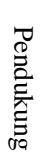 & 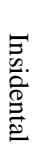 & & & & & 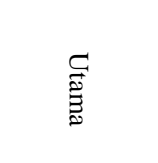 & 胥 & 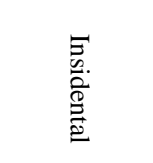 \\
\hline & & & $\mathrm{a}$ & $\mathrm{b}$ & $\mathrm{c}$ & $\mathrm{A}$ & B & $\mathrm{C}$ & $\mathrm{D}$ & axAxbxCxD & bxAxBxCxD & $\operatorname{cxAxBxCxD}$ \\
\hline 1 & $\begin{array}{c}\text { Pengambilan } \\
\text { Material }\end{array}$ & Harian & 1 & 0 & 0 & 1 & 5 & 1 & 240 & 1200 & 0 & 0 \\
\hline 2 & Setting Mesin & Harian & 1 & 0 & 0 & 1 & 30 & 1 & 240 & 7200 & 0 & 0 \\
\hline 3 & Produksi & Harian & 1 & 0 & 0 & 1 & 300 & 1 & 240 & 72000 & 0 & 0 \\
\hline 4 & Pembersihan & Harian & 1 & 0 & 0 & 1 & 30 & 1 & 240 & 7200 & 0 & 0 \\
\hline 5 & $\begin{array}{c}\text { Pengecekan } \\
\text { Rutin }\end{array}$ & Harian & 1 & 0 & 0 & 21 & 15 & 1 & 240 & 75600 & 0 & 0 \\
\hline 6 & Sanitasi & Harian & 1 & 0 & 0 & 2 & 60 & 1 & 240 & 28800 & 0 & 0 \\
\hline 8 & Pelatihan & Tahunan & 0 & 0 & 1 & 1 & 60 & 1 & 12 & 0 & 0 & 720 \\
\hline \multicolumn{10}{|c|}{ Beban Kerja } & 192000 & 0 & 720 \\
\hline
\end{tabular}

